Original Research Paper

\title{
Direct Acting Anti-Viral Drugs Improve Health-Related Quality of Life in Patients' with Hepatitis C
}

\author{
${ }^{1}$ Wesam Morad, ${ }^{2}$ Warda Othman, ${ }^{2}$ Esam Elshimi and ${ }^{2}$ Nashwa Shebl \\ ${ }^{1}$ Department of Epidemiology and Preventive Medicine, National Liver Institute, Menoufia University, Egypt \\ ${ }^{2}$ Department of Hepatology, National Liver Institute, Menoufia University, Egypt
}

Article history

Received: 21-02-2020

Revised: 04-04-2020

Accepted: 28-04-2020

Corresponding Author:

Wesam Saber Morad

Department of Epidemiology

and Preventive Medicine,

National Liver Institute,

Menoufia University, Egypt

Email: Dr.warda82@yahoo.com

\begin{abstract}
Chronic hepatitis C Virus (HCV) causes significant decline in the Health Related Quality of Life (HRQL). Recently, direct Acting Anti-viral Drugs (DAA) have been endorsed as standard of care for treatment for HCV. To study the HRQL in patients with HCV and cirrhosis before and after DAA. Study design: Prospective cohort hospital based study. We included 500 patients with HCV and cirrhosis fulfilled all eligibility criteria for treatment and completed the survey of HRQL using (SF-36 and CLDQ questioners) before and after treatment. Patients were treated by combination of one of the following regimens: (a) Sofosbuvir (SOF) plus Daclatasvir (DAC) \pm Ribavirin (RBV) in 2 divided doses or (b) SOF plus Simeprevir (SIM) \pm RBV or c) SOF plus RBV. On treatment, $35.2 \%$ of the patients had a poor physical function and half of them had poor role-emotional, while $45.7 \%$ patients' had excellent roleemotional, $49 \%$ noticed change in their mode, evaluation of HRQL before and after treatment through SF-36 and CLDQ showed an improvement in different domains. $(p<0.05)$. The overall Sustained Virological Response (SVR) was (89.6\%). Results from the current study suggest that HRQL decreased on treatment and significantly increased after treatment. We recommend addressing the patients' quality of life into consideration as a part of the evaluation protocol before the initiation of DAA drugs and after cure to improve this particular aspect of patients' life.
\end{abstract}

Keywords: HCV, DAA Drugs, Liver Cirrhosis, Quality of Life

\section{Introduction}

Given $\mathrm{HCV}$, is recognized as a major national and international health burden and represents around $14.7 \%$ prevalence rate among the general population in Egypt (Mohamoud et al., 2013) with estimated worldwide prevalence of 150-170 million (Chack et al., 2011). On one hand, HCV infection can lead to a diversity of hepatic related complications that ranged from mild form of chronic hepatitis to liver cirrhosis and hepatocellular carcinoma, with estimated mortality up to 350,000 people/year (Cacoub et al., 1999). On the other hand, HCV may promote a panel of extra-hepatic manifestations, two-thirds of infected patients experienced extra-hepatic manifestations at some time point of course of disease (Cacoub et al., 1999). Some of these manifestation are well documented and more common, while others are infrequent (Cacoub et al., 1999; 2000; Zignego et al., 2007). Soon after HCV discovery, HCV-related autoimmune or lymphoproliferative disorders, from benign mixed cryoglobulinemia to frank lymphomas, have been reported
(Zignego et al., 2007; Terrier and Cacoub, 2004; Zignego and Brechot, 1999). Patients with HCV infection and associated extra hepatic manifestations have shown higher morbidity and mortality rates than patients with HCV alone (Maasoumy and Wedemeyer, 2012; Uto et al., 2009; Bonkovsky and Woolley, 1999; Svirlith et al., 2008). Moreover patients with HCV infection have reported significant decline of the key dimensions of their quality of life (DiBonaventura et al., 2010; Hsu et al., 2012; Chong et al., 2013; Bezemer et al., 2012; Ware et al., 1999; Carithers et al., 1996; Forton, 2011; Senzolo et al., 2011).

Many patients with chronic HCV infection report unexplained symptoms including dyspepsia, fatigue, irritability, anorexia, nausea, headache muscle ache. These symptoms have been shown to negatively impact patients' psychological well-being and quality of life (Bouffard et al., 1992; Foster et al., 1998).

Given the association of aforementioned extra hepatic comorbidities in absence of severity of liver disease, nonviral factors such as psychiatric and stigmatization elements associated with acquisition of the virus, may explain part of 
decline of quality of life associated with HCV (Younossi et al., 2007; Adinolfi et al., 2012). HCV infection may be associated with the release of inflammatory cytokines and altered serotonergic and dopaminergic neurotransmission (Backus et al., 2011).

Health-related quality of life has also been reported to be influenced by the patient's awareness of a serious illness (Hsu et al., 2014).

Many clinical findings have shown that, viral eradication significantly reduced the rate of extra hepatic deaths (Kallman et al., 2007; Rodger et al., 1999; Rasenack et al., 2003; Hassanein et al., 2004). Recent therapeutic advances in the treatment of $\mathrm{HCV}$, with the possibility to eradicate $\mathrm{HCV}$ following newly introduced DAA (Feeney and Chung, 2014) appears of major importance, for hepatic and extra hepatic manifestations. The HRQL in patients with HCV and cirrhosis before and after DAA wasn't studied.

\section{Methods}

\section{A-Subjects}

From March 2016 to March 2018; 19.443 patients with chronic HCV infection have been evaluated for participation in National Egyptian program for treatment for HCV at National Liver Institute' hospital-Menoufia University-Egypt. Among this number, 2127 patients have liver cirrhosis, from this number of patients, 780 met our inclusion criteria have HCV infection, naïve cases with no previous treatment, with no other chronic diseases and agreed to sign the consent form to participate in the current study, 620 patients started DAAs treatment, but only 582 started the study. Finally, 500 patients fulfilled all eligibility criteria of starting DAAs treatment and completed the survey before and after the end of treatment.

All patients tested positive for antibodies to $\mathrm{HCV}$ in addition to having circulating HCV-RNA as measured by RT-PCR, all patients were geno-type 4 and lacked the clinical or laboratory indices of advanced liver disease according to the current national Egyptian program for treatment of HCV. All patients have Metavir score of F3 and F4 based on fibroscan results prior to initiation of treatment.

Exclusion criteria included: age under 18 or above 70 years, associated another liver diseases as co-infections with HBV, patients with diseases known to cause decline the quality of life as cancers, psychiatric illness, autoimmune disease, ischemic heart disease, addicts. Patients with depression were also excluded based on the validated Arabic version of Hospital Anxiety and Depression Scale (Terkawi et al., 2017).

\section{Procedures}

\section{Assessment of $H R Q L$}

Patients' who initially agreed, were interviewed by a trained research assistants and they were asked to sign an
Arabic consent form in the presence of one of authors. The consent form stated that the answers would be anonymous and the obtained results would be used only for scientific research. For comprehensive assessment of HRQL, the Short Form-36 (SF-36) and The Chronic Liver Disease Quality score (CLDQ) were applied before and after treatment.

A-,SF-36 Health Survey summary score. It is a simple an interviewer-administrated multidimensional questionnaire. It comprises 36 items from 8 dimensions, (Physical Functioning (PF), Mental Health (MH), General Health (GH), bodily Pain (P), Role Physical (RP), Social Functioning (SF), Vitality (V), Role Emotional (RE), Results are expressed as a score ranging from 0 to 100 for each of the 8 dimensions, the higher scores is indicator of better quality of life (Lins and Carvalho, 2016).

B-,CLDQ is a disease-targeted measures focuses on aspects of HRQL relevant to liver disease. It is composed of 29 questions distributed in 6 domains (abdominal symptoms, fatigue, (systemic symptoms, activity, emotional function and worry. according to severity. Scores range from 1 (worst) to 7 (best), in which higher scores indicate better quality of life. The overall score is calculated by sum of average of the six dimensions (Campolina et al., 2011; Häuser et al., 2004).

\section{DAA Drugs}

Patients were treated by combination of one of the following regimens: (a) Single daily oral dose of $400 \mathrm{mg}$ of Sofosbuvir (SOF) plus single daily oral dose of $60 \mathrm{mg}$ of Daclatasvir (DAC) \pm RBV $(12-15 \mathrm{mg} / \mathrm{kg} /$ day in 2 divided doses or (b) single daily oral dose of $400 \mathrm{mg}$ SOF plus single daily oral dose of $150 \mathrm{mg}$ Simeprevir (SIM) \pm weight based ribavirin (RBV as mentioned before) or (c) single daily oral dose of $400 \mathrm{mg}$ SOF plus weight based Ribavirin (RBV as mentioned before). Patients were treated for 12 weeks or 24 weeks based on the committee of treatment protocol. All patients were followed up during treatment every 4 weeks and at the end of treatment, clinically and by laboratory investigations.

Follow up: Patients were followed up by the research team at 12 weeks and 24 weeks after the end of treatment. Adverse events and treatment discontinuation were reported. All collected data were documented in clinical records, specifically designed for the current study. The end-line survey was done 24 weeks after the end of the treatment.

\section{Data Collection}

A baseline and disease history data of the participants. Baseline data included age, time of diagnosis, other comorbidities, marital status, sex and education. The history related to the disease comprised previous treatments and respective responses, assessment of hepatic impairment, stage of liver fibrosis and/or presence of cirrhosis, presence 
of extra-hepatic manifestations and quantitative viral load (HCV-RNA). During the follow up period of every 4 weeks during the treatment and at 12 weeks and 24 weeks after end of treatment, patients were evaluated for safety outcomes and most commonly reported adverse events such as headache, loss of appetite, shivering, skin rash, nausea, Fever, diarrhea and other problems. Also data of 36 QOL items from 8 dimensions, (Physical Functioning (PF), Mental Health (MH), General Health (GH), bodily Pain (P), Role Physical (RP), Social Functioning (SF), vitality (V), Role Emotional (RE) were collected during the follow up period of every 4 weeks during the treatment and at 12 weeks and 24 weeks after end of treatment.

\section{Statistical Analysis}

Data recorded in Microsoft Office Excel were processed and then transferred to the SPSS software version 26, in which all statistical tests were performed. Qualitative variables were expressed as absolute and relative frequencies and quantitative variables were presented as means and Standard Deviations (SD).

The Kolmogorov-Smirnov test was used to verify the normality distribution of the studied parameters. Nonparametric tests were applied in the comparative analysis as data wasn't normally distributed. Wilcoxon-related samples test was used for statistical analysis of the HRQoL instruments which allowed the comparison of HRQoL within a single group of patients, in which domains were evaluated in pairs, with values referring to before and after treatment, for each instrument. MannWhitney U test was performed to compare quality of life in patients receiving different treatments. For all analyses, the significance level of $p<0.05$ was adopted, with a confidence level of $95 \%$.

\section{Results}

\section{Baseline Characteristics}

All baseline characteristics, socio-demographic data, degree of fibrosis and treatment response were presented in (Table 1). Most of the studied patients were males (420 out of 500 patients), most of them were treated with SOF/DAC $\pm \mathrm{RBV}$ in 300 patients, 190 patients were treated with $\mathrm{SOF} / \mathrm{SIM} \pm \mathrm{RBV}$ and 10 patients received SOF/RBV, 395 patients were treated for 12 weeks, Metavir score was F3 in most of cases (278 patients), 310 patients (62\%) of cases were not responders to interferon based therapy.

Table 1: Socio-demographic and clinical variables of the study population

\begin{tabular}{|c|c|}
\hline Parameter & Total patients $(n-=500)$ \\
\hline \multicolumn{2}{|l|}{ Gender, n (\%) } \\
\hline Male & $420(84 \%)$ \\
\hline Female & $80(16 \%)$ \\
\hline \multicolumn{2}{|l|}{ Age, n (\%) } \\
\hline $18-34$ & $25(5 \%)$ \\
\hline $35-54$ & $250(50 \%)$ \\
\hline $55-74$ & $225(45 \%)$ \\
\hline Mean age (SD) years & $42.8 \pm 8.2$ \\
\hline \multicolumn{2}{|l|}{ Treatment received, $\mathrm{n}(\%)$} \\
\hline $\mathrm{SOF}+\mathrm{DAC} \pm \mathrm{RBV}$ & $300(68 \%)$ \\
\hline $\mathrm{SOF}+\mathrm{SMV} \pm \mathrm{RBV}$ & $190(30 \%)$ \\
\hline $\mathrm{SOF}+\mathrm{RBV}$ & $10(2 \%)$ \\
\hline Time since diagnosis, years (SD) & $12.87 \pm 10.07$ \\
\hline \multicolumn{2}{|l|}{ Treatment duration, $\mathrm{n}(\%)$} \\
\hline $12 \mathrm{w}$ & $395(79 \%)$ \\
\hline $24 \mathrm{w}$ & $105(21 \%)$ \\
\hline \multicolumn{2}{|l|}{ Metavir, n (\%) } \\
\hline F3 & $278(55.6 \%)$ \\
\hline F4 & $222(44.4 \%)$ \\
\hline Patients previously treated, $\mathrm{n}(\%)$ & $310(62 \%)$ \\
\hline Viral load $\geq 800.000$ IU mL-1, n (\%) & $240(48 \%)$ \\
\hline \multicolumn{2}{|l|}{ Marital status, n (\%) } \\
\hline Married & $470(94 \%)$ \\
\hline Not Married (Single, Separated, Widowed) & $30(6 \%)$ \\
\hline \multicolumn{2}{|l|}{ Educational level, n (\%) } \\
\hline Illiterate & $60(12 \%)$ \\
\hline Elementary school & $90(18 \%)$ \\
\hline Secondary school & $185(37 \%)$ \\
\hline High school & $165(33 \%)$ \\
\hline Patients with addictions, $\mathrm{n}(\%)$ & $0(0 \%)$ \\
\hline
\end{tabular}

$50 \%$ of the patients were between 35-54 years old

Abbreviations: RBV: Ribavirin; SOF: Sofosbuvir; SMV: Simeprevir 
On treatment, about $35.2 \%$ of the patients had a poor physical function and about half of them had poor role-emotional, while $45.7 \%$ patients' had excellent role-emotional, $49 \%$ noticed change in their mode and about $5 \%$ felt depressed to the extent of suicide, about $(27 \%)$ had fair bodily-pain, $(32.0 \%)$ had fair general health and $(27 \%)$ had poor general health, $47.0 \%$ had poor vitality, $35.0 \%$ of patients had excellent social functioning, whereas (about 65.0\%) ranging from poor to fair social functioning, about $(36.0 \%)$ had poor mental health (Table 2).
The evaluation of HRQL before and after treatment through SF-36 showed an improvement in different domains. We noticed that the HRQL was improved after treatment, patients with SVR gained significantly better scores in most of dimensions of SF-36 and CLDQ instruments (Table 3).

In SF-36 score, an increase in patients' HRQL in six of the eight domains was noticed $(p<0.05)$. In four of domains of CLDQ score: EF, WO, SS and overall score, patients presented significantly higher averages after treatment $(p<0.05)$.

Table 2: Distribution of patients attending National Liver Institute Hospital according to SF 36 scales $(\mathrm{N}=500)$

\begin{tabular}{|c|c|c|c|}
\hline SF 36 scales & score & No. & $\%$ \\
\hline \multirow[t]{5}{*}{ Physical Functioning } & $(85-100 \%)$ & 120 & 24 \\
\hline & $(75-<85 \%)$ & 70 & 14 \\
\hline & $(65-<75 \%)$ & 55 & 11 \\
\hline & $(50-<65 \%)$ & 80 & 16 \\
\hline & $(<50 \%)$ & 175 & 35 \\
\hline \multirow[t]{5}{*}{ Role-Physical } & $(85-100 \%)$ & 160 & 32 \\
\hline & $(75-<85 \%)$ & 20 & 4 \\
\hline & $(65-<75 \%)$ & 0 & 0 \\
\hline & $(50-<65 \%)$ & 55 & 11 \\
\hline & $(<50 \%)$ & 265 & 53 \\
\hline \multirow[t]{5}{*}{ Role-Emotional } & $(85-100 \%)$ & 230 & 46 \\
\hline & $(75-<85 \%)$ & 0 & 0 \\
\hline & $(65-<75 \%)$ & 20 & 4 \\
\hline & $(50-<65 \%)$ & 0 & 0 \\
\hline & $(<50 \%)$ & 250 & 50 \\
\hline \multirow[t]{5}{*}{ Bodily-Pain } & $(85-100 \%)$ & 120 & 24 \\
\hline & $(75-<85 \%)$ & 25 & 5 \\
\hline & $(65-<75 \%)$ & 90 & 18 \\
\hline & $(50-<65 \%)$ & 135 & 27 \\
\hline & $(<50 \%)$ & 130 & 26 \\
\hline \multirow[t]{5}{*}{ General Health } & $(85-100 \%)$ & 0 & 0 \\
\hline & $(75-<85 \%)$ & 75 & 15 \\
\hline & $(65-<75 \%)$ & 130 & 26 \\
\hline & $(50-<65 \%)$ & 160 & 32 \\
\hline & $(<50 \%)$ & 135 & 27 \\
\hline \multirow[t]{5}{*}{ Vitality } & $(85-100 \%)$ & 60 & 12 \\
\hline & $(75-<85 \%)$ & 50 & 10 \\
\hline & $(65-<75 \%)$ & 45 & 9 \\
\hline & $(50-<65 \%)$ & 110 & 22 \\
\hline & $(<50 \%)$ & 235 & 47 \\
\hline \multirow[t]{5}{*}{ Social Functioning } & $(85-100 \%)$ & 175 & 35 \\
\hline & $(75-<85 \%)$ & 40 & 8 \\
\hline & $(65-<75 \%)$ & 0 & 0 \\
\hline & $(50-<65 \%)$ & 140 & 28 \\
\hline & $(<50 \%)$ & 145 & 29 \\
\hline \multirow[t]{5}{*}{ Mental Health } & $(85-100 \%)$ & 75 & 15 \\
\hline & $(75-<85 \%)$ & 60 & 12 \\
\hline & $(65-<75 \%)$ & 75 & 15 \\
\hline & $(50-<65 \%)$ & 110 & 22 \\
\hline & $(<50 \%)$ & 180 & 36 \\
\hline
\end{tabular}


Another analysis was performed to compare the quality of life in patients receiving different treatments SOF/DAC versus SOF/SIM, with or without RBV), patients' receiving $\mathrm{SOF} / \mathrm{DAC} \pm \mathrm{RBV}$ had significantly lower scores before and after treatment compared to the ones receiving SOF/SIM (Table 4).

\section{Outcomes Regarding Treatment Effectiveness and Safety}

SVR was found in 448 out of 500 patients (89.6\%). Regarding treatment regimens, 264 out of 300 patients who received SOF/DAC $\pm \mathrm{RBV}, 174$ out of 190 patients who received $\mathrm{SOF} / \mathrm{SMV} \pm \mathrm{RBV}$ and 10 out of 10 patients who received SOF/RBV achieved SVR ( $88 \%$ and $91.58 \%$ and $100 \%$ respectively). Only forty five of the 500 patients $(9.0 \%)$ who were evaluated for safety outcomes did not present any adverse events. 270 patients $(54 \%)$ sought medical advices for annoying side effects (Fig. 1). The most commonly reported adverse events during treatment were headache $(55 \%)$, loss of appetite $(36 \%)$, shivering $(20 \%)$, skin rash $(16 \%)$, nausea $(22 \%)$, Fever $(24 \%)$, diarrhea $(25 \%)$ and other problems $(60 \%)$. No patients discontinued treatment due to adverse events (Fig. 2).

Table 3: Comparison of SF-36 and CLDQ scores between patients before and after treatment $(\mathrm{N}=500)$

\begin{tabular}{|c|c|c|c|c|c|c|c|}
\hline \multicolumn{2}{|c|}{ Domains of SF-36 and CLDQ } & \multirow{2}{*}{$\begin{array}{l}\begin{array}{l}\text { Before } \\
\text { treatment }\end{array} \\
52.1( \pm 64.5)\end{array}$} & \multirow{2}{*}{$\begin{array}{l}\begin{array}{l}\text { After } \\
\text { treatment }\end{array} \\
70.3( \pm 26.3)\end{array}$} & \multirow{2}{*}{$\frac{p \text {-value }}{0.04 *}$} & \multirow{2}{*}{$\begin{array}{l}\text { Treatment } \\
\text { responders }\end{array}$} & \multirow{2}{*}{$\begin{array}{l}\text { Treatment Non } \\
\text {-responders } \\
55.3( \pm 24.3)\end{array}$} & \multirow{2}{*}{$\frac{\mathrm{p} \text {-value }}{0.03^{*}}$} \\
\hline SF-36 & PF & & & & & & \\
\hline & $\mathrm{PH}$ & $43.1( \pm 42.1)$ & $62.5( \pm 42.6)$ & $0.01 *$ & $68.3( \pm 43.2)$ & $44.7( \pm 39.6)$ & $0.01 *$ \\
\hline & $\mathrm{P}$ & $53.6( \pm 26.1)$ & $63.4( \pm 25.7)$ & $0.005^{*}$ & $76.4( \pm 22.5)$ & $60.2( \pm 22.3)$ & $0.02 *$ \\
\hline & GH & $55.3( \pm 25.2)$ & $61.6( \pm 24.2)$ & $0.001 *$ & $81.2( \pm 21.2)$ & $60.7( \pm 26.2)$ & $0.001 *$ \\
\hline & V & $51.4( \pm 27.1)$ & $62.3( \pm 25.5)$ & $0.006^{*}$ & $66.3( \pm 22.5)$ & $52.3( \pm 24.9)$ & $0.03 *$ \\
\hline & SF & $65.6( \pm 32.4)$ & $74.2( \pm 33.2)$ & 0.07 & $79.6( \pm 30.4)$ & $69.3( \pm 32.8)$ & $0.04 *$ \\
\hline & EW & $46.8( \pm 46.2)$ & $53.6( \pm 44.6)$ & 0.09 & $55.1( \pm 41.3)$ & $47.1( \pm 45.1)$ & $0.046^{*}$ \\
\hline & MH & $59.2( \pm 23.9)$ & $68.1( \pm 21.9)$ & $0.005^{*}$ & $71.1( \pm 22.2)$ & $63.2( \pm 23.3)$ & $0.003 *$ \\
\hline \multirow[t]{7}{*}{ CLDQ } & AS & $4.08( \pm 1.82)$ & $4.11( \pm 1.76)$ & 0.8 & $4.43( \pm 1.75)$ & $4.11( \pm 1.68)$ & 0.05 \\
\hline & FA & $3.44( \pm 1.68)$ & $3.81( \pm 1.74)$ & 0.08 & $3.92( \pm 1.71)$ & $3.63( \pm 1.65)$ & 0.06 \\
\hline & AT & $4.36( \pm 1.72)$ & $4.52( \pm 1.84)$ & 0.5 & $4.73( \pm 1.86)$ & $4.37( \pm 1.74)$ & 0.07 \\
\hline & $\mathrm{EF}$ & $3.75( \pm 1.66)$ & $4.08( \pm 1.84)$ & $0.006^{*}$ & $4.24( \pm 1.79)$ & $3.79( \pm 1.81)$ & $0.003 *$ \\
\hline & WO & $3.62( \pm 1.72)$ & $5.05( \pm 1.61)$ & $0.001 *$ & $5.51( \pm 1.75)$ & $3.76( \pm 1.65)$ & $0.001 *$ \\
\hline & SS & $4.09( \pm 1.37)$ & $4.49( \pm 1.24)$ & $0.03 *$ & $4.55( \pm 1.26)$ & $4.11( \pm 1.27)$ & $0.04 *$ \\
\hline & Overall score & $3.88( \pm 1.29)$ & $4.35( \pm 1.23)$ & $0.002 *$ & $4.55( \pm 1.24)$ & $3.94( \pm 1.26)$ & $0.003 *$ \\
\hline
\end{tabular}

Note: ${ }^{*} p<0.05$. Abbreviations: AS: Abdominal Symptoms; AT: Activity; EW: Emotional Well-being; EF: Emotional Function; FA: Fatigue; GH: General Health; MH: Mental Health; P: Pain; PF: Physical Functioning; PH: Role limitations due to physical health; SF: Social Functioning; SS: Systemic Symptoms; V: Vitality; WO: Worry

Table 4: Comparison of SF-36 and CLDQ scores between SOF/DAC versus SOF/SMV patients before and after treatment (N = 500)

\begin{tabular}{|c|c|c|c|c|c|c|c|}
\hline \multicolumn{2}{|c|}{ Domains of SF-36 and CLDQ } & \multirow{2}{*}{$\begin{array}{l}\begin{array}{l}\text { Before } \\
\text { treatment }\end{array} \\
52.1( \pm 64.5)\end{array}$} & \multirow{2}{*}{$\begin{array}{l}\begin{array}{l}\text { After } \\
\text { treatment }\end{array} \\
70.3( \pm 26.3)\end{array}$} & \multirow{2}{*}{$\frac{\mathrm{p} \text {-value }}{0.04^{*}}$} & \multirow{2}{*}{$\begin{array}{l}\begin{array}{l}\text { Treatment } \\
\text { responders }\end{array} \\
78.9( \pm 23.7)\end{array}$} & \multirow{2}{*}{$\begin{array}{l}\text { Treatment Non- } \\
\text { responders }\end{array}$} & \multirow{2}{*}{$\frac{p \text {-value }}{0.03^{*}}$} \\
\hline SF-36 & $\mathrm{PF}$ & & & & & & \\
\hline & PH & $43.1( \pm 42.1)$ & $62.5( \pm 42.6)$ & $0.01 *$ & $68.3( \pm 43.2)$ & $44.7( \pm 39.6)$ & $0.01 *$ \\
\hline & $\mathrm{P}$ & $53.6( \pm 26.1)$ & $63.4( \pm 25.7)$ & $0.005^{*}$ & $76.4( \pm 22.5)$ & $60.2( \pm 22.3)$ & $0.02 *$ \\
\hline & GH & $55.3( \pm 25.2)$ & $61.6( \pm 24.2)$ & $0.001 *$ & $81.2( \pm 21.2)$ & $60.7( \pm 26.2)$ & $0.001 *$ \\
\hline & $\mathrm{V}$ & $51.4( \pm 27.1)$ & $62.3( \pm 25.5)$ & $0.006^{*}$ & $66.3( \pm 22.5)$ & $52.3( \pm 24.9)$ & $0.03 *$ \\
\hline & SF & $65.6( \pm 32.4)$ & $74.2( \pm 33.2)$ & 0.07 & $79.6( \pm 30.4)$ & $69.3( \pm 32.8)$ & $0.04 *$ \\
\hline & EW & $46.8( \pm 46.2)$ & $53.6( \pm 44.6)$ & 0.09 & $55.1( \pm 41.3)$ & $47.1( \pm 45.1)$ & $0.046^{*}$ \\
\hline & MH & $59.2( \pm 23.9)$ & $68.1( \pm 21.9)$ & $0.005^{*}$ & $71.1( \pm 22.2)$ & $63.2( \pm 23.3)$ & $0.003 *$ \\
\hline \multirow[t]{7}{*}{ CLDQ } & AS & $4.08( \pm 1.82)$ & $4.11( \pm 1.76)$ & 0.8 & $4.43( \pm 1.75)$ & $4.11( \pm 1.68)$ & 0.05 \\
\hline & FA & $3.44( \pm 1.68)$ & $3.81( \pm 1.74)$ & 0.08 & $3.92( \pm 1.71)$ & $3.63( \pm 1.65)$ & 0.06 \\
\hline & $\mathrm{AT}$ & $4.36( \pm 1.72)$ & $4.52( \pm 1.84)$ & 0.5 & $4.73( \pm 1.86)$ & $4.37( \pm 1.74)$ & 0.07 \\
\hline & $\mathrm{EF}$ & $3.75( \pm 1.66)$ & $4.08( \pm 1.84)$ & $0.006^{*}$ & $4.24( \pm 1.79)$ & $3.79( \pm 1.81)$ & $0.003 *$ \\
\hline & WO & $3.62( \pm 1.72)$ & $5.05( \pm 1.61)$ & $0.001 *$ & $5.51( \pm 1.75)$ & $3.76( \pm 1.65)$ & $0.001 *$ \\
\hline & SS & $4.09( \pm 1.37)$ & $4.49( \pm 1.24)$ & $0.03 *$ & $4.55( \pm 1.26)$ & $4.11( \pm 1.27)$ & $0.04 *$ \\
\hline & Overall score & $3.88( \pm 1.29)$ & $4.35( \pm 1.23)$ & $0.002 *$ & $4.55( \pm 1.24)$ & $3.94( \pm 1.26)$ & $0.003 *$ \\
\hline
\end{tabular}

Note: $* p<0.05$. Abbreviations: AS: Abdominal Symptoms; AT: Activity; EW: Emotional Well-being; EF: Emotional Function; FA: Fatigue; GH: General Health; MH: Mental Health; P: Pain; PF: Physical Functioning; PH: Role limitations due to physical health; SF: Social Functioning; SS: Systemic Symptoms; V: Vitality; WO: Worry 


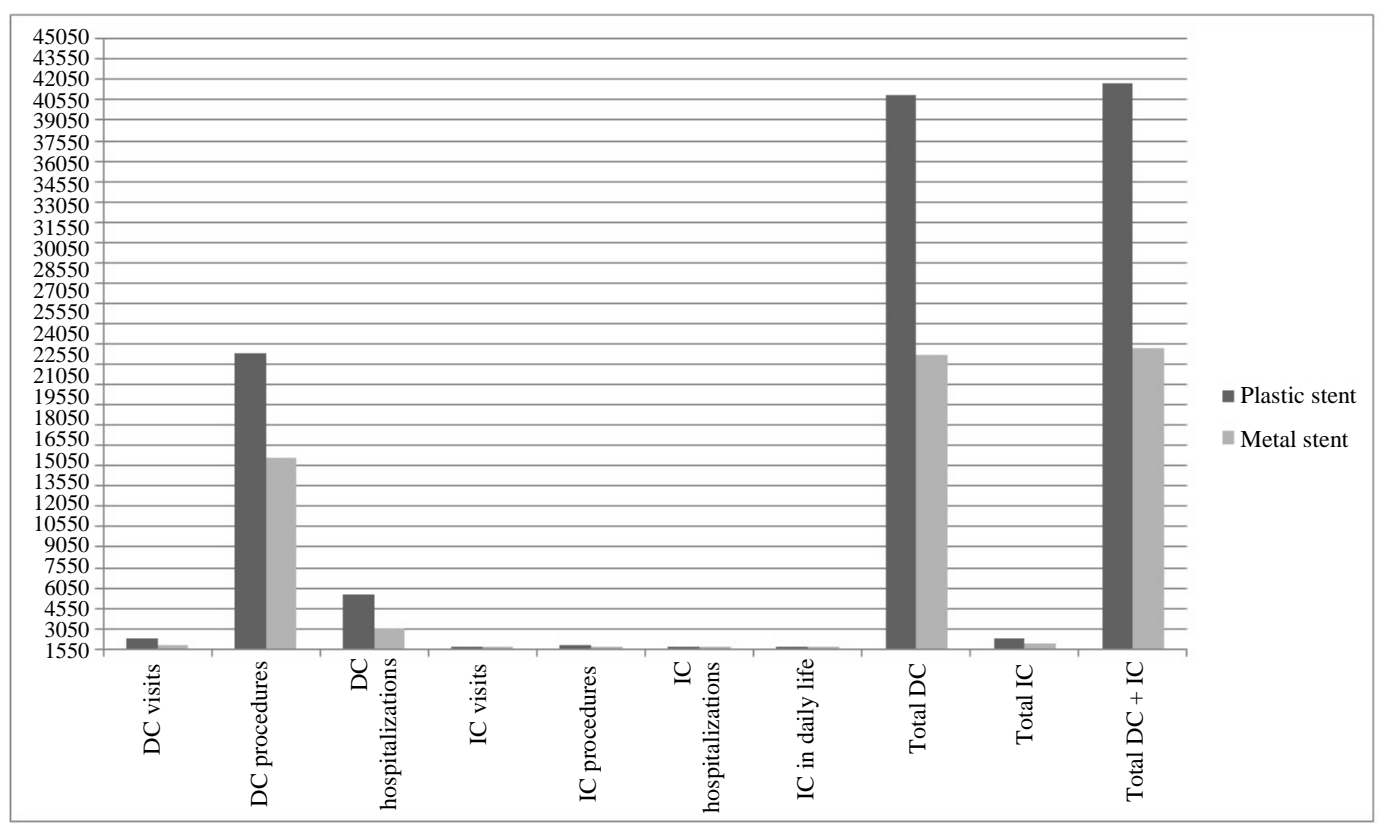

Fig. 1: Distribution of patients consulted the doctor about annoying side effects $(\mathrm{N}=500), 54 \%$ of patients consulted the doctor about annoying side effects

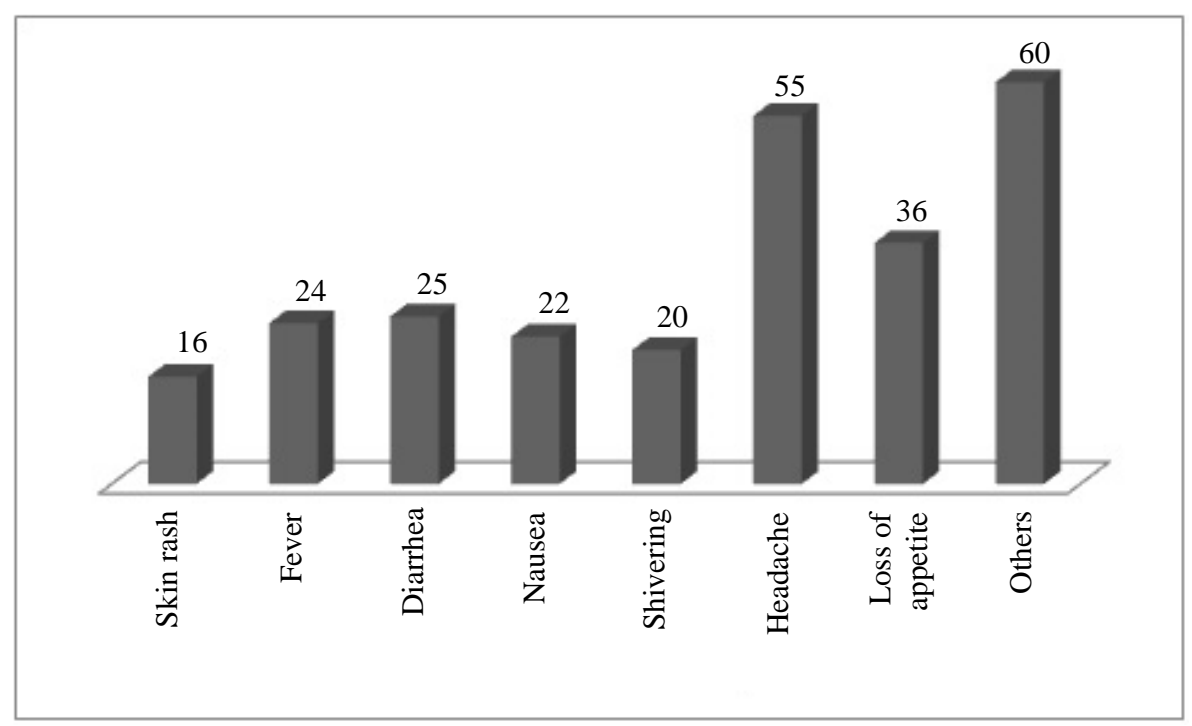

Fig. 2: Distribution of common short-term side effects among patients attending National Liver Institute Hospital (N=500). Headache was the most common short-term side effect (55\%) followed by others as (joint pain-decreasing sexual function-decreasing appetite)

\section{Discussion}

The concept of quality-of-life in health had been introduced in 1970 as an outcome measure in healthcare development in the context of medical progress (Panzini et al., 2017). Given the progress brings an increment in life expectancy and acute illness previously lethal could be curable and chronic diseases could also be efficiently controlled. Consequently, HRQL has become of great significance to evaluate how patients live their 'next times (Fallowfield, 1990). HRQL has intersections with functional and biological aspects, such as disability, health and functional statuses, social and psychological concepts such as well-being, happiness and satisfaction. Moreover, the American Food and Drug Administration have emphasized that, the HRQL should be considered when evaluating the outcomes of chronic disease and the impact of therapeutic modalities (Wilson and Cleary, 1996). The 
HRQL can be classified as generic or disease specific. Generic measures are tailored to comparing patient groups across different diseases and for comparing diseased to healthy people, the disease-specific measures are suited to determination of the efficacy of treatment modalities for a specific disease (Drossman, 1996).

In recent years, hundreds of thousands of Egyptians have been recruited for the current Egyptian national program for combating $\mathrm{HCV}$ infection, aimed at reducing the prevalence of $\mathrm{HCV}$ and eradication by 2030. The plenty of affordable generic DAAs in Egypt allowed us to recruit patients from the National Liver Institute, a nationally representative, well-equipped government university center. The DAA drugs have been emerged in recent years, however the treatment regimens have undergone numerous changes. The interferon-free schemes, have been approved in 2014 in terms of significantly better SVR with less adverse events and adherence to therapy when compared to previous regimens (WHO, 2016; Osoba, 1999; Gralnek et al., 2000). Moreover, in patients with cirrhosis or advanced fibrosis with SVR, the histologic analysis and or elastography showed that the fibrosis stage of $\mathrm{HCV}$-infected patients was improved, consequently, improvement of HRQL is expected based on expected improvement of the synthetic power of liver in cured patients (Mascia et al., 2017; Manuscr Dolmazashvili et al., 2017; Tada et al., 2017).

From this context, we evaluated 500 Egyptian patients with chronic HCV infection and cirrhosis. We matched our patients in terms of factors that might influence the responses on the HRQL questionnaires, including age, educational level, socioeconomic class, Matavir score and previous treatments with interferon based therapy, all studied patients were treated with the three approved regimens at the time of study conduction namely, $\mathrm{SOF} / \mathrm{DAC}$ with or without RBV, SOF/SIM with or without RBV and SOF/RBV in small number of patients.

In the present study, none of the studied patients discontinued treatment and the aforementioned regimens have wide safety margins, however, we have found that significant proportions of patients developed significant adverse effects and about 5\% of them felt depressed to the extent of suicide during the period of treatment based on the results of SF-36. Our studied patients, experienced marked improvement after treatment than before treatment based on the SF-36 results, either in the total score or in most of its sub domains $(p<0.05)$. Additionally, patients also presented significantly higher averages after treatment than before treatment $(p<0.05)$ in the overall score and in some domains of CLDQ: Namely EF, WO, SS.

In the sub analysis of our findings, the quality of life in patients receiving SOF/DAC with or without RBV had significantly lower scores before and after treatment compared to patients receiving SOF/SIM.
In the study population, a minority of patients $(9.0 \%)$ did not present any adverse events, considerable number of patients, (54\%) sought medical advice for some distressing adverse effects during treatment: headache (55\%), loss of appetite (36\%), shivering (20\%), skin rash $(16 \%)$, nausea $(22 \%)$, fever $(24 \%)$, diarrhea $(25 \%)$ and other problems $(60 \%)$. However all of the aforementioned adverse effects were self-limited.

The over-all SVR in our study population was (89.6.\%). Regarding treatment regimens, the SVR was in $\mathrm{SOF} / \mathrm{DAC} \pm \mathrm{RBV}, \mathrm{SOF} / \mathrm{SIMV} \pm \mathrm{RBV}$ and $\mathrm{SOF} / \mathrm{RBV}$ got SVR of $(88 \%, 91.58 \%$ and $100 \%)$ respectively). Given all of the study' populations are cirrhotic and were classified in the category of difficult to treat, moreover, significant number of them were non responders to interferon based therapy.

Our findings supported the results of Siqueira et al. (2018), who discussed the quality of life during the treatment with DAA drugs and by the same regimens, however their study was limited by inclusion of small number of patients and the heterogeneity of study population by inclusion of patients with and without cirrhosis and associated comorbidities, the aforementioned factors may confound the results during and after treatment.

Our findings clearly supported the superiority of SOF/SIM as it related to patients' HRQL when compared to other regimens. Given the SOF/DAC was considered as the treatment modality in patients with advanced cirrhosis, in fact, patients treated with second generation DAA drugs with (FN-free regimen) have a rapid improvement of their HRQL scores after treatment.

In our study patients with SVR gained better HRQL than non-responders. The SVR, induced as an impact of $\mathrm{HCV}$ clearance, has been linked to the positive impacts of disease progression and survival outcomes, in addition SVR normalizes the elevated low-level of inflammatory cytokines and optimizes metabolites at the level of basal ganglia, that in turn improves the cerebral immune activation and cognitive function among patients who clear the virus (Foster et al., 1998; Spiegel et al., 2005).

In the era of DAA, similar studies have been conducted in different geographical areas with use of different or similar regimens (Ferreira et al., 2018a; 2017; 2018b). Our findings are consistent with the data reported for patients with $\mathrm{HCV}$ worldwide who had been treated with the same regimens (Poordad et al., 1973; Younossi et al., 2014; Gerber et al., 2016; Younossi et al., 2016a; 2016b; Poordad et al., 2014). However, the direct comparison between the cohorts is difficult given the cohorts are not matched with different baseline clinical and socio-demographic characteristics in addition to use of different instruments in assessment of HRQL. 
Many limitations are notable in this study, first, the use of English versions of SF 36 and CLDQ scores with Egyptian patients with native Arabic language tacked substantial effort for translation, second, the patients had different baseline characteristics and different treatment regimens, third the different age groups among the study population with different dimensions of HRQL. Moreover our study and others suffered from the lacking of standardized instruments for assessment of HRQL among patients with liver disease.

The many strengths of the current study include its status as the first to estimate an extensive assessment of HRQL in Egyptian patients with HCV related cirrhosis treated with interferon free regimens plus the exclusion of other comorbidities that confound the result. Moreover we compared between responders and non-responders in term of HRQL. The relatively large number of the study population, re-enforces the validity of our study.

\section{Conclusion}

DAA therapies have wide safety margins in the treatment of patients with $\mathrm{HCV}$ and cirrhosis. Results from the current study suggest that HRQL decreased during the therapy and significantly increased after treatment. Patients with SVR have significantly better HRQL than non-responders. We recommend addressing the patients' quality of life into consideration as a part of the evaluation protocol before the initiation of DAA therapy and after cure to improve this particular aspect of patients' life. Finally, it is important for hepatologists and health educators to encourage the patients to voice their concerns about quality of life, especially given the comings of potent and safer DDA drugs.

\section{Data Availability Statement}

1. The data used to support the findings of this study were supplied by National Liver Institute, Menoufia University under license and so cannot be made freely available. Requests for access to these data should be made to [National Liver Institute Top manager, Menoufia Governorate, Egypt].

2. The qualitative and quantitative data used to support the findings of this study are restricted by the [National Liver Institute ETHICS BOARD] in order to protect [PATIENT PRIVACY]. Data are available from [National Liver Institute Top manager, Menoufia Governorate, Egypt] for researchers who meet the criteria for access to confidential data.

3. The qualitative and quantitative data used to support the findings of this study are available from the corresponding author upon request for researchers who meet the criteria for access to confidential data.

4. The qualitative and quantitative data used to support the findings of this study have not been made available because [National Liver Institute Top manager].

\section{Acknowledgment}

We wish to thank all the patients and medical staff who participated in this study.

\section{Funding Information}

This paper was funded by the authors of the paper themselves with no funding agency or funded personnel.

\section{Authors' Contributions}

Wesam Morad: Contributed to study concept, design and data collection and statistical analysis and interpretation of the data.

Wesam Morad, Esam Elshimi, Nashwa Shebl and Warda Othman: Were clinical investigators in the study. All authors contributed to writing of the papers and WM critically revised and finalized paper and all authors read and approved the final manuscript.

\section{Ethical Approval}

The study protocol was approved by the ethics committee (for medical research) of Würzburg University in accordance with the Declaration of Helsinki and the Institutional Review Board of the National Liver Institute, Menoufia University-Egypt, (IRB number IRB00003413).

\section{Ethics Approval and Consent to Participate}

This study was conducted in accordance with the International Conference on Harmonisation guideline for good clinical practice and the ethical principles of the Declaration of Helsinki. All patients gave written informed consent, which was reviewed and approved by an independent ethics committee or institutional review board of National Liver Institute (IRB00003413). This study was approved (approval numbers 00125/2017.

\section{Consent for Publication}

Patients provided written informed consent for use of their anonymized and aggregated data for research and sharing with other parties.

\section{References}

Adinolfi, L., L. Restivo, R. Zampino, B. Guerrera and A. Lonardo et al., 2012. Chronic HCV infection is a risk of atherosclerosis. Role of $\mathrm{HCV}$ and $\mathrm{HCV}$-related steatosis. Atherosclerosis, 221: 496502-496502. DOI: $10.1016 / \mathrm{j}$.atherosclerosis.2012.01.051

Backus, L., D. Boothroyd, B. Phillips, P. Belperio and J. Halloran et al., 2011. A sustained virologic response reduces risk of all-cause mortality in patients with hepatitis C. Clin. Gastroenterol. Hepatol., 9: 509516-509516. DOI: $10.1016 /$ j.cgh.2011.03.004 
Bezemer, G., A.R. van Gool, E. Verjeij-Hart, B.E Hansen and Y. Lurie et al., 2012. Long-term effects of treatment and response in patients with chronic hepatitis $\mathrm{C}$ on quality of life: An international, multicenter, randomized, controlled study. BMC Gastroenterol., 12: 11-11.

DOI: $10.1186 / 1471-230 X-12-11$

Bonkovsky, H.L. and J.M. Woolley, 1999. The consensus interferon study group. Reduction in health-related quality of life in chronic hepatitis $\mathrm{C}$ and improvement with interferon therapy. The Consensus Interferon Study Group. Hepatology, 29: 264-270. DOI: 10.1002/hep.510290124

Bouffard, P., P. Hayashi, R. Acevedo N. Levy and J.B. Zeldis, 1992. Hepatitis C virus is detected in monocyte/macrophage subpopulation of peripheral blood mononuclear cells of infected patients. J. Infect. Dis., 166: 1276-1282. DOI: 10.1093/infdis/166.6.1276

Cacoub, P., C. Renou, E. Rosenthal, P. Cohen and I. Loury et al., 2000. Extrahepatic manifestations associated with hepatitis $\mathrm{C}$ virus infection. A prospective multicenter study of 321 patients. The GERMIVIC. Grouped Etude et de Rechercheen Medecine Internet Maladies Infectieuses surle Virus de l'Hepatite C. Med., 79: 4756-4756.

Cacoub, P., T. Poynard, P. Ghillani, F. Charlotte and M. Olivi et al., 1999. Extrahepatic manifestations of chronic hepatitis C. MULTIVIRC Group. Multi. Virus C. Arthritis Rheum., 42: 22042212-22042212.

DOI: $10.1002 / 1529-0131(199910) 42: 10<2204:: A I D-$ ANR24>3.0.CO;2-D

Campolina, A.G., A.B. Bortoluzzo, M.B. Ferraz and R.M. Ciconelli, 2011. Validação da versão brasileira do questionário genérico de qualidade de vida shortform 6 dimensions (SF-6D Brasil). Cienc Saude Coletiva, 16: 3103-3110.

DOI: 10.1590/S1413-81232011000800010

Carithers, R.L., D. Sugano and M. Bayliss, 1996. Health assessment for chronic HCV: Results of HQL. Digestive Dis. Sci., 41: 75S-80S.

DOI: $10.1007 / \mathrm{BF} 02087879$

Chack, E., A.H. Talal, K.E. Sherman, E.R. Schiff and S. Saab, 2011. Hepatitis C virus infection in USA: An estimate of true prevalence. Liver Int., 31: 1090-1001. DOI: $10.1111 / \mathrm{j} .1478-3231.2011 .02494 . x$

Chong, C.A., A. Gulamhussein and E.J. Heathcote, 2003. Health-state utilities and quality of life in hepatitis C patients. Am. J. Gastroenterol., 98: 630-638. DOI: 10.1111/j.1572-0241.2003.07332.x

DiBonaventura, M.D., J.S. Wagner, Y. Yuan, G. LItalien and P. Langley et al., 2010. Humanistic and economic impacts of hepatitis $\mathrm{C}$ infection in the United States. J. Med. Econ., 13: 709-718.

Drossman, D.A., 1996. Gastrointestinal illness and the biopsychosocial model. J. Clin. Gastroenterol., 22: 252-254. DOI: 10.1097/00004836-199606000-00002
Fallowfield, L., 1990. The quality of life: The missing measurement in health care. Souvenir Press, London, England.

Feeney, E.R. and R.T. Chung, 2014. Antiviral treatment of hepatitis C. BMJ, 348: 3308-3308. DOI: $10.1136 /$ bmj.g3308

Ferreira, V.L., F.S. Tonin, N.A. Assis Jarek, Y. Ramires and R. Pontarolo, 2017. Effcacy of interferon-free therapies for chronic hepatitis $C$ : A systematic review of all randomized clinical trials. Clin. Drug Invest., 37: 635-646. DOI: $10.1007 / \mathrm{s} 40261-017-0521-4$

Ferreira, V.L., L.P. Leonart, F.S. Tonin, H.H. Borba and R. Pontarolo, 2018a. Sustained virological response in special populations with chronic hepatitis $\mathrm{C}$ using interferon-free treatments: A systematic review and meta-analysis of observational cohort studies. Clin. Drug Invest., 38: 389-400. DOI: $10.1007 / \mathrm{s} 40261-018-0624-6$

Ferreira, V.L., H.H. Borba, A. Wiens, M.L. Pedroso and V.F. Radunz et al., 2018b. Effectiveness and tolerability of directacting antivirals for chronic hepatitis $\mathrm{C}$ patients in a Southern state of Brazil. Brazil J. Infect. Dis., 22: 186-921. DOI: $10.1016 /$ j.bjid.2018.04.003

Forton, D.M., 2011. Hepatitis C treatment-clearing the mind. J. Hepatol., 56: 513-514. DOI: 10.1016/j.jhep.2011.11.004

Foster, G.R., R.D. Goldin and H.C. Thomas, 1998. Chronic hepatitis $\mathrm{C}$ virus infection causes a significant reduction in quality of life in the absence of cirrhosis. Hepatology, 27: 209-212.

Gerber, L., M. Estep and M. Stepanova, 2016. Effects of viral eradication with ledipasvir and sofosbuvir, with or without ribavirin, on measures of fatigue in patients with chronic hepatitis $\mathrm{C}$ virus infection. Clin. Gastroenterol. Hepatol., 14: 156-164.

Gralnek, I.M., R.D. Hays, A. Kilbourne, H.R Rosen and E.B. Keeffe et al., 2000. Development and evaluation of the Liver disease quality of life instrument in persons with advanced, chronic liver disease-the LDQOL 1.0. Am. J. Gastroenterol., 95: 3554-3565. DOI: 10.1016/S0002-9270(00)02168-7

Hassanein, T., G. Cooksley, M. Sulkowski, C. Smith and G. Marinos et al., 2004. The impact of peginterferon alfa- 2 a plus ribavirin combination therapy on health-related quality of life in chronic hepatitis C. J. Hepatol., 40: 675-681.

DOI: $10.1016 / \mathrm{j} . j$ hep.2003.12.014

Häuser, W., G. Holtmann and D. Grandt, 2004. Determinants of health-related quality of life in patients with chronic liver diseases. Clin. Gastroenterol. Hepatol., 2: 157-163. DOI: $10.1016 / \mathrm{S} 1542-3565(03) 00315-\mathrm{X}$ 
Hsu, P.C., C.A. Federico, M. Krajden, E.M. Yoshida and K.E. Bremner et al., 2012. Health utilities and psychometric quality of life in patients with earlyand late-stage hepatitis $\mathrm{C}$ virus infection. $\mathrm{J}$. Gastroenterol. Hepatol., 27: 149-57.

DOI: 10.1111/j.1440-1746.2011.06813.X

Hsu, Y., J. Lin, H. Ho, Y. Kao and Y. Huang et al., 2014. Antiviral treatment for hepatitis $\mathrm{C}$ virus infection is associated with improved renal and cardiovascular outcomes in diabetic patients. Hepatology, 59: 12931302-12931302.

DOI: $10.1002 /$ hep.26892

Kallman, J., M. O’Neil, B. Larive, N. Boparai and L. Calabrese et al., 2007. Fatigue and health-related quality of life (HRQL) in chronic hepatitis $\mathrm{C}$ virus infection. Digestive Dis. Sci., 52: 25312539-25312539. DOI: $10.1007 / \mathrm{s} 10620-006-9708-\mathrm{x}$

Lins, L. and F.M. Carvalho, 2016. SF-36 total score as a single measure of health-related quality of life: Scoping review. SAGE Open Med., 4: $2050312116671725-2050312116671725$.

DOI: $10.1177 / 2050312116671725$

Maasoumy, B. and H. Wedemeyer, 2012. Natural history of acute and chronic hepatitis C. Best Pra. Res. Clin. Gastroenterol., 26: 401412-401412.

DOI: $10.1016 /$ j.bpg.2012.09.009

Manuscr Dolmazashvili, E., A. Abutidze, N. Chkhartishvili, K. Marine and Sharvadze et al., 2017. Regression of liver fibrosis over a 24-week period after completing direct-acting antiviral therapy in patients with chronic hepatitis $\mathrm{C}$ receiving care within the national hepatitis $\mathrm{C}$ elimination program in Georgia: Results of hepatology clinic HEPA experience. Eur. J.

Mascia, C., S. Vita, P. Zuccala, R. Marocco and T. Tieghi et al., 2017. Changes in inflammatory biomarkers in $\mathrm{HCV}$-infected patients undergoing direct acting antiviral-containing regimens with or without interferon. PLoS One, 12: e0179400-e0179400.

DOI: 10.1371/journal.pone.0179400

Mohamoud, Y.A., G.R. Mumtaz, S. Riome, D. Miller and L.J. Abu-Raddad, 2013. The epidemiology of hepatitis $\mathrm{C}$ virus in Egypt: A systematic review and data synthesis. BMC Infect. Dis., 13: 288-288.

DOI: 10.1186/1471-2334-13-288

Osoba, D., 1999. Guidelines for Measuring HealthRelated Quality of Life in Clinical Trials. In: Quality of Life Assessment in Clinical Trials, Staquet, M.J., R.D. Hays and P.M. Fayers (Eds.), Oxford University Press, New York, pp: 19-36.

Panzini, R.G.1., B.P.1. Mosqueiro, R.R.1. Zimpel, D.R.2. Bandeira and N.S.1. Rocha et al., 2017. Quality-of-life and spirituality. Int. Rev. Psychiatry, 29: 263-282. DOI: 10.1080/09540261.2017.1285553
Poordad, F., C. Hezode, R. Trinh, K.V. Kowdley and S. Zeuzem et al., 1973. ABT-450/r-ombitasvir and dasabuvir with ribavirin for hepatitis C with cirrhosis. N Engl. J. Med., 370: 1973-1982. DOI: $10.1056 /$ NEJMoa1402869

Poordad, F., C. Hezode, R. Trinh, K.V. Kowdley and S. Zeuzem et al., 2014. ABT-450/r-ombitasvir and dasabuvir with ribavirin for hepatitis $\mathrm{C}$ with cirrhosis. N Engl. J. Med., 370: 1973-1982.

DOI: $10.1056 /$ NEJMoa1402869

Rasenack, J., S. Zeuzem, S.V. Feinman, E.J. Heathcote and M. Manns et al., 2003. Peginterferon alpha-2a (40kD) [Pegasys] improves HR-QOL outcomes compared with unmodified interferon alpha-2a [Roferon-A]: In patients with chronic hepatitis C. Pharmacoeconomics, 21: 341-349. DOI: 10.2165/00019053-200321050-00005

Rodger, A.J., D. Jolley, S.C. Thompson, A. Lanigan and N. Crofts, 1999. The impact of diagnosis of hepatitis C virus on quality of life. Hepatology, 30: 1299-1301. DOI: $10.1002 /$ hep.510300504

Senzolo, M., S. Schiff and C.M. DAloiso, 2011. Neuropsychological alterations in hepatitis $\mathrm{C}$ infection: The role of inflammation. World J. Gastroenterol., 17: 3369-3374. DOI: 10.3748/wjg.v17.i29.3369

Siqueira, F.M., V.L. Ferreira, H.H.L. Borba and R. Pontarolo, 2018. Quality of life of Brazilian chronic hepatitis $\mathrm{C}$ patients treated with interferon-free therapies. Rev. Inst. Med. Trop Sao Paulo., 14: e72-e72. DOI: 10.1590/s1678-9946201860072

Spiegel, B.M., Z.M. Younossi, R.D. Hays, D. Revicki and S. Robbins et al., 2005. Impact of hepatitis C on health related quality of life: A systematic review and quantitative assessment. Hepatology, 41: 790-800. DOI: 10.1002/hep.20659

Svirlith, N., S. Pavic and D. Terzic, 2008. Reduced quality of life in patients with chronic viral liver disease as assessed by the SF-12 questionnaire. J. Gastrointest. Liver Dis., 17: 405-409.

Tada, T., T. Kumada, H. Toyoda, K. Mizuno and Y. Sone et al., 2017. Improvement of liver stiffness in patients with hepatitis $\mathrm{C}$ virus infection who received direct-acting antiviral therapy and achieved sustained virological response. J. Gastroenterol. Hepatol., 32: 1982-1988. DOI: $10.1111 /$ jgh.13788

Terkawi, A.S., S. Tsang, G.J. AlKahtani, S.H. Al-Mousa and S. Al Musaed et al., 2017. Development and validation of Arabic version of the hospital anxiety and depression scale. Saudi J. Anaesth., 11: S11-S18. DOI: 10.4103/sja.SJA_43_17

Terrier, B. and P. Cacoub, 2004. Renal involvement in HCV-related vasculitis. Clin. Res. Hepatol. Gastroenterol., 37: 334339-334339. 
Uto, H., S. Stuver, K. Hayashi, K. Kumagai and F. Sasaki et al., 2009. Increased rate of death related to presence of viremia among hepatitis $\mathrm{C}$ virus antibody-positive subjects in a community-based cohort study. Hepatology, 50: 393399-393399. DOI: $10.1002 /$ hep. 23002

Ware, J.E.J., M.S. Bayliss, M. Mannocchia and G.L. Davis, 1999. Health-related quality of life in chronic hepatitis C: Impact of disease and treatment response. Int. Therapy Group Hepatology., 30: 550-555. DOI: $10.1002 /$ hep.510300203

WHO, 2016. World Health Organization Guidelines for the screening, care and treatment of persons with chronic hepatitis C infection: Updated version, guidelines. WHO, Geneva.

Wilson, I.B. and P.D. Cleary, 1996. Linking clinical variables with health-related quality of life. JAMA, 273: 59-65. DOI; 10.1001/jama.1995.03520250075037

Younossi, Z., J. Kallman and J. Kincaid, 2007. The effects of HCV infection and management on healthrelated quality of life. Hepatology, 45: 806-816. DOI: 10.1002/hep.21565

Younossi, Z.M., M. Stepanova and L. Henry, 2014. Effects of sofosbuvir-based treatment, with and without interferon, on outcome and productivity of patients with chronic hepatitis C. Clin. Gastroenterol. Hepatol., 12: 1349-1359.
Younossi, Z.M., M. Stepanova, S. Pol, J.P. Bronowicki and M.P. Carrieri et al., 2016a. The impact of ledipasvir/ sofosbuvir on patient-reported outcomes in cirrhotic patients with chronic hepatitis C: The SIRIUS study. Liver Int., 36: 42-48. DOI: $10.1111 /$ liv.12886

Younossi, Z.M., M. Stepanova, M. Sulkowski, G.R. Foster and G.R. Foster et al., 2016b. Ribavirin-free regimen with sofosbuvir and velpatasvir is associated with high efficacy and improvement of patient-reported outcomes in patients with genotypes 2 and 3 chronic hepatitis C: Results from astral-2 and -3 clinical trials. Clin. Infect. Dis., 63: 1042-1048. DOI: $10.1093 / \mathrm{cid} / \mathrm{ciw} 496$

Zignego, A. and C. Brechot, 1999. Extrahepatic manifestations of HCV infection: Facts and controversies. J. Hepatol., 31: 369376-369376. DOI: $10.1016 / \mathrm{S} 0168-8278(99) 80239-6$

Zignego, A., C. Ferri, S. Pileri, P. Caini and F. Bianchi, 2007. Italian Association of the study of liver commission on extrahepatic manifestations of $\mathrm{HCV}$ infection. Extrahepatic Manifestations Hepatitis C virus Infec. General Over. Guidelines Clin. Approach Digestive Liver Dis., 39: 217-217. DOI: $10.1016 /$ j.dld.2006.06.008 